\title{
La antropología forense al servicio de la justicia y la historia: las fosas de la Guerra Civil
}

\section{Forensic anthropology serving justice and history: the Spanish Civil War mass graves}

\section{Resumen}

La antropología forense tiene por objeto tanto la identificación del individuo, como la determinación de la causa y circunstancias de la muerte. En este sentido, la antropología forense es esencial para la recuperación de los restos de personas desaparecidas y que fueron enterrados en fosas comunes durante la Guerra Civil y la dictadura franquista, para su posterior retorno a los familiares.

En este trabajo se presentan los resultados de la intervención llevada a cabo en la fosa de Gurb, en la que fueron enterrados cuatro soldados republicanos vecinos de Gavà y cuyos familiares habían solicitado su exhumación. El trabajo multidisciplinar llevado a cabo permitió: 1) recuperar toda la información ante mortem disponible en relación a la fosa y los desaparecidos, 2) recuperar mediante metodología arqueológica y directrices antropológico-forenses los restos de los 13 individuos enterrados en la fosa, y 3 ) analizar los restos en el laboratorio a través de técnicas antropológicas, forenses, moleculares y de superposición craneofacial. Los resultados permitieron tanto la identificación de las cuatro personas buscadas, como la determinación de las causas y circunstancias de su muerte, relacionadas todas ellas con heridas por arma de fuego, acaecidas en un contexto de batalla.

Palabras clave: DNA. Morfología. Superposición craneofacial. Guerra Civil.

\section{Abstract}

Forensic Anthropology seeks both to identify the individual, such as determining the cause and circumstances of death. In this sense, forensic anthropology is essential for recovery remains of missing persons who were buried in mass graves during the Spanish Civil War and Franco's dictatorship, for subsequent return to their families.

This paper presents the results of work done at the grave of Gurb, where Republican soldiers were buried; four families of Gavà had applied for exhumation of their relatives buried in it. The multidisciplinary work carried out allowed us: 1 ) to retrieve all available ante mortem information regarding the pit and the missing persons, 2) to recover the remains of 13 individuals buried in the grave by archaeological methods and forensic-anthropological guidelines, and 3 ) to analyze their remains in the laboratory through anthropological, forensics, molecular and craniofacial superimposition techniques. The results allowed both the identification of the four wanted persons, such as determining the causes and circumstances of his death, in all cases due to battle related trauma, specifically firearm injuries.

Key words: DNA. Morphology. Craniofacial duplication. Civil War.
A. Malgosa ${ }^{1}$
N. Armentano ${ }^{1}$
I. Galtés ${ }^{1,2}$
X. Jordana ${ }^{1,3}$
M. Subirana ${ }^{1,2}$
E. Gassiot ${ }^{4}$
M. Luna 5
C. Lalueza 6
Q. Solé7

${ }^{1}$ Unidad de Antropología biológica. Dpto. Biología Animal, Biología Vegetal y Ecología. Universitat Autònoma de Barcelona.

${ }^{2}$ Institut de Medicina Legal de Catalunya.

${ }^{3}$ Dpto. de Paleobiología. Institut Català de Paleontologia ${ }^{4}$ Dpto. Prehistoria. Universitat Autònoma de Barcelona. ${ }^{5}$ Dpto. Salud Pública. Univ. de Barcelona. ${ }^{6}$ nstituto de Biología Evolutiva (CSIC-UPF).

${ }^{7}$ Dpto. Historia

Contemporánea. Univ. de Barcelona.

\section{Correspondencia:}

Dra. Assumpció Malgosa. E-mail:

assumpcio.malgosa@uab.cat

Fecha de recepción: 18.MAR.2010

Fecha de aceptación: 18.MAR.2010
La antropología forense es una subdisciplina de la antropología biológica o física y, como parte de esta disciplina, estudia la diversidad humana a nivel biológico, pero en su vertiente de aplicación práctica utiliza estos conocimientos para encontrar las diferencias, establecer individualidades y, en definitiva, 
identificar personas. También contribuye a detectar los signos traumáticos que pueden llevar a establecer la causa y circunstancias de la muerte ${ }^{1}$.

En el Estado español, la antropología forense sólo es reconocida a nivel legal, si es ejercida por un médico forense. De hecho su formación docente ha estado y sigue estando vinculada a la medicina forense. En otros países, como Portugal o Estados Unidos, la antropología forense tiene una entidad propia, tanto a nivel de enseñanza, como profesional. De todas maneras, en la actualidad, el avance de la ciencia en general hacia la interdisciplinariedad nos encamina hacia una colaboración estrecha entre todos los ámbitos del saber. Por tanto, la antropología forense está a medio camino entre la antropología física y la medicina forense; sin embargo, este encuadre no estaría completo si no añadimos aquí el universo del derecho.

Teniendo en cuenta sus relaciones con otras ciencias, la antropología forense puede contribuir tanto a la identificación de una persona viva o de un cadáver relativamente reciente, como auxiliar a la historia mediante la identificación de personajes de la antigüedad $^{2,3,4}$. Pero sin quedarnos tan cerca, ni alejarnos tanto en el tiempo, tenemos sobre la mesa un problema grave en el que la antropología forense puede ser de inestimable ayuda: las desapariciones forzadas. A nivel internacional, la ONU tiene un Grupo de Trabajo sobre Desapariciones Forzadas o Involuntarias (Working Group on Enforced or InvoIuntary Disappearances). Es el más antiguo de los "Procedimientos Especiales de la Comisión de Derechos Humanos" instituidos por los diversos órganos

Figura 1

Fosa de Gurb antes de iniciar los trabajos de excavación.

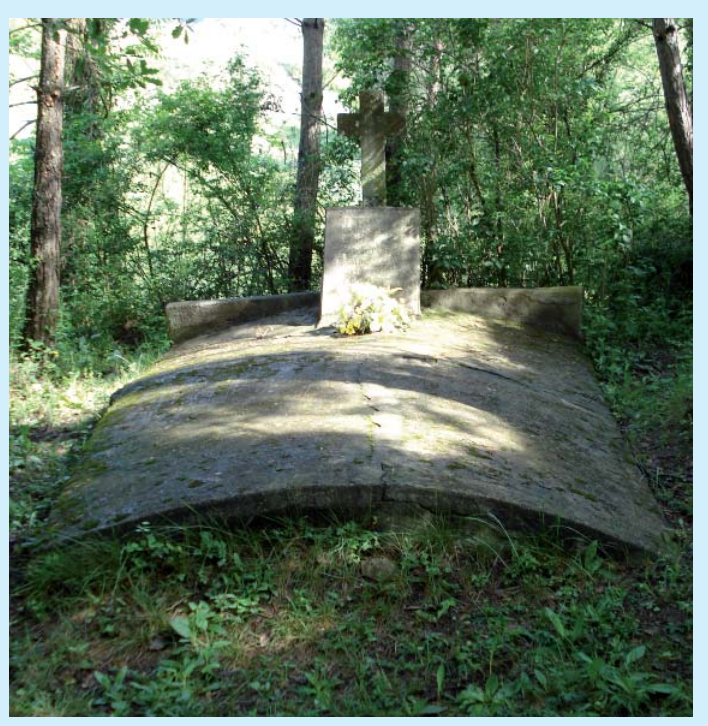

de Naciones Unidas, encargado expresamente desde 1980 del examen y vigilancia en nombre de la comunidad internacional de las desapariciones forzadas a nivel mundial, así como de informar pública y regularmente del estado de esta cuestión. Más tarde, en 1996, se constituyó la Comisión Internacional sobre Personas Desaparecidas (ICMP) fundada para apoyar el Acuerdo de Paz de Dayton que puso fin al conflicto en Bosnia-Herzegovina. Además de su trabajo en los países de la ex-Yugoslavia, la ICMP está implicada en la ayuda a gobiernos y otras instituciones en varias partes del mundo a afrontar cuestiones sociales y políticas relativas a las personas desaparecidas, estableciendo métodos de identificación efectivos tras un conflicto armado o un desastre natural. En diversos países existen equipos con funciones similares, entre los que destaca el Equipo Argentino de Antropología Forense (EAAF).

Volviendo la vista hacia nuestro país, existen casos en los que la antropología forense cumple también ese papel entre la justicia y la historia: son las fosas de la Guerra Civil. En este sentido, la llamada ley de la Memoria histórica (Ley 52/2007, de 26 de diciembre) y la ley catalana (Llei 10/2009, de 30 de juny) sobre la localización y la identificación de las personas desaparecidas durante la Guerra Civil y la dictadura franquista, pone en evidencia la necesidad de la intervención de la antropología forense en este tema.

\section{La fosa de Gurb}

Paralelamente a la tramitación de la ley catalana sobre las fosas de la Guerra Civil, se realizó una prueba piloto a fin de establecer los parámetros de actuación imprescindibles y la problemática inherente a estas actuaciones, a partir de un conocimiento empírico. Por ello, en mayo de 2008 se procedió a la apertura de la fosa de Gurb, Osona, Barcelona (Figura 1). Esta fosa contenía los restos humanos de cómo mínimo cuatro vecinos de la población de Gavà (JS, GV, AO, JR), que fueron movilizados por el ejército de la República y que el 2 de febrero de 1939 murieron al enfrentarse al avance de las tropas sublevadas, en los alrededores de Gurb.

La fosa de Gurb es, pues, una fosa de retirada republicana, ubicada fuera de cementerio. Se encuentra cerca de la masía de Can Cadet, en un rellano al margen de una riera ${ }^{5}$. Gracias al testimonio de dos supervivientes, los familiares pudieron conocer el lugar exacto dónde fueron enterrados los cuatro vecinos de Gavà, y dignificar la fosa común con una construcción y una lápida en la que se hizo constar sus nombres. 




Figura 2.

Composición multidisciplinar del equipo de investigación que intervino en la fosa de Gurb. Equipos y dirección de las diferentes tareas.
El proyecto de exhumación e identificación encargado se basó en tres etapas de actuación (Figura 2):

- La investigación sobre la documentación ante mortem de los desaparecidos a fin de disponer de datos de comparación para la eventual identificación.

- La excavación y exhumación, con el objetivo de recuperar los restos y los documentos y objetos que les acompañan y, a su vez, obtener los primeros datos identificativos y reconstruir las circunstancias y las causas de muerte.

- Los análisis de laboratorio para conseguir la identificación de los cuatro desaparecidos y establecer los datos informativos en el ámbito forense.

Para el proyecto se organizó el equipo de técnicos y especialistas necesario para lograr el objetivo principal, la recuperación e identificación de los cuatro vecinos de Gavà. Así pues, el proyecto se abordó desde una perspectiva interdisciplinar cuyo núcleo estaba formado por historiadores, arqueólogos, antropólogos y forenses (Figura 2) que trabajaron en los tres ámbitos citados:

- La obtención de los datos ante mortem estuvo liderada por un médico forense, experto en el tipo de información necesaria para una identificación y en cómo obtenerla, a la vez que formado en aspectos legales y en el trato con personas que han sufrido situaciones difíciles.
- La exhumación tuvo una triple dirección, arqueológica, antropológica y forense, con el fin de conseguir los tres objetivos previstos: recuperar los restos con garantías arqueológicas, y reconstruir les evidencias que la misma excavación destruye; recuperar los restos humanos sin pérdida de información antropológica y obtener sobre el terreno los primeros datos.

- El estudio de las evidencias se efectuó en distintos laboratorios especializados; algunos análisis se realizaron secuencialmente, mientras que otros pudieron ser procesados de forma paralela. Los laboratorios implicados fueron: antropológicos, forenses, genéticos, de superposición craneofacial, objetos y balística.

\section{Metodología}

La investigación histórica fue realizada por el Centre d'Estudis Històrics de Gavà. La recogida de la documentación para la identificación se realizó mediante una ficha de información/datos ante mortem durante las entrevistas con los familiares. Así mismo, se reconstruyeron los árboles genealógicos de los desaparecidos con el fin de solicitar las muestras biológicas para los análisis genéticos, previa firma de un documento de consentimiento informado elaborado a tal efecto. 
La intervención arqueológica se estructuró en diversas fases: 1) Confirmación de la localización de la fosa por distintos métodos históricos y geofísicos; 2) Documentación del contexto, con especial referencia a la relación entre los restos esqueléticos y los diferentes tipos de artefactos existentes, así como de la superposición entre individuos dentro la fosa; y 3) Exhumación de los restos humanos combinado con la documentación antropológica.

Respecto a la documentación de los esqueletos se realizó un registro de las superposiciones existentes entre los esqueletos, generando una matriz análoga a las utilizadas para las descripciones de las relaciones estratigráficas mediante el Sistema Harris ${ }^{6}$ y se infirió el orden en que los cuerpos fueron introducidos en la fosa. Por otro lado, se realizó la planimetría de la disposición de los diferentes esqueletos en el interior de la fosa, mediante la ortogeoreferenciación de las imágenes fotográficas cenitales de los diferentes individuos.

La representación planimétrica se completó en el laboratorio. Cada imagen se importó a un archivo AutoCAD y, a partir de las coordenadas de cada individuo, se procedió a realizar la escala, la rotación y el encaje de la imagen en su posición a partir del sistema de referencia empleado en el campo (Figura 3).

Para la excavación de los restos antropológicos se utilizó una ficha antropológica para documentar tota la información arqueológica, tafonómica y antropoló- gica de cada individuo ${ }^{7,8}$ que se corroboró en el laboratorio. También se realizó una descripción, un registro fotográfico y una interpretación preliminar de las lesiones esqueléticas, a fin de determinar su cronología y origen. Se documentaron asimismo los elementos entomológicos que fueron localizados, identificados y muestreados.

La metodología, tanto en el registro de los datos como en los diagnósticos, fue la habitual de los procedimientos de antropología clásica y forense ${ }^{9-11}$. En este sentido, cabe destacar el tratamiento especial otorgado a las muestras para el análisis de ADN. Todas las muestras fueron recogidas por el mismo investigador, utilizando guantes y mascarilla quirúrgica, y almacenadas en contenedores estériles en condiciones de baja temperatura. Complementariamente a las actuaciones técnicas específicas, se siguió una estricta cadena de custodia que continuó en el laboratorio.

El estudio antropológico de laboratorio consistió en elaborar un perfil biológico de cada uno de los individuos. El sexo se diagnosticó a partir de las características morfológicas de la región pélvica y craneal $^{11,12}$ y secundariamente se aplicaron funciones discriminantes ${ }^{13-15}$. Para el diagnóstico de la edad se utilizaron los criterios basados en la fusión epifisaria ${ }^{7,16}$, el desarrollo dental ${ }^{10,17}$ y los cambios morfológicos de la sínfisis púbica ${ }^{18-20}$, la superficie auricular ${ }^{21,22}$ y el extremo esternal de la cuarta costilla ${ }^{23,24}$. Los rangos de edad se categorizaron en:

Figura 3.

Dibujo del individuo 4 sobre una fotografía ortogeoreferenciada a partir de los puntos de referencia.

El dibujo reproduce tanto la posición anatómica y las dimensiones de los diferentes elementos esqueléticos como otros aspectos (fracturas, objetos, etc.).

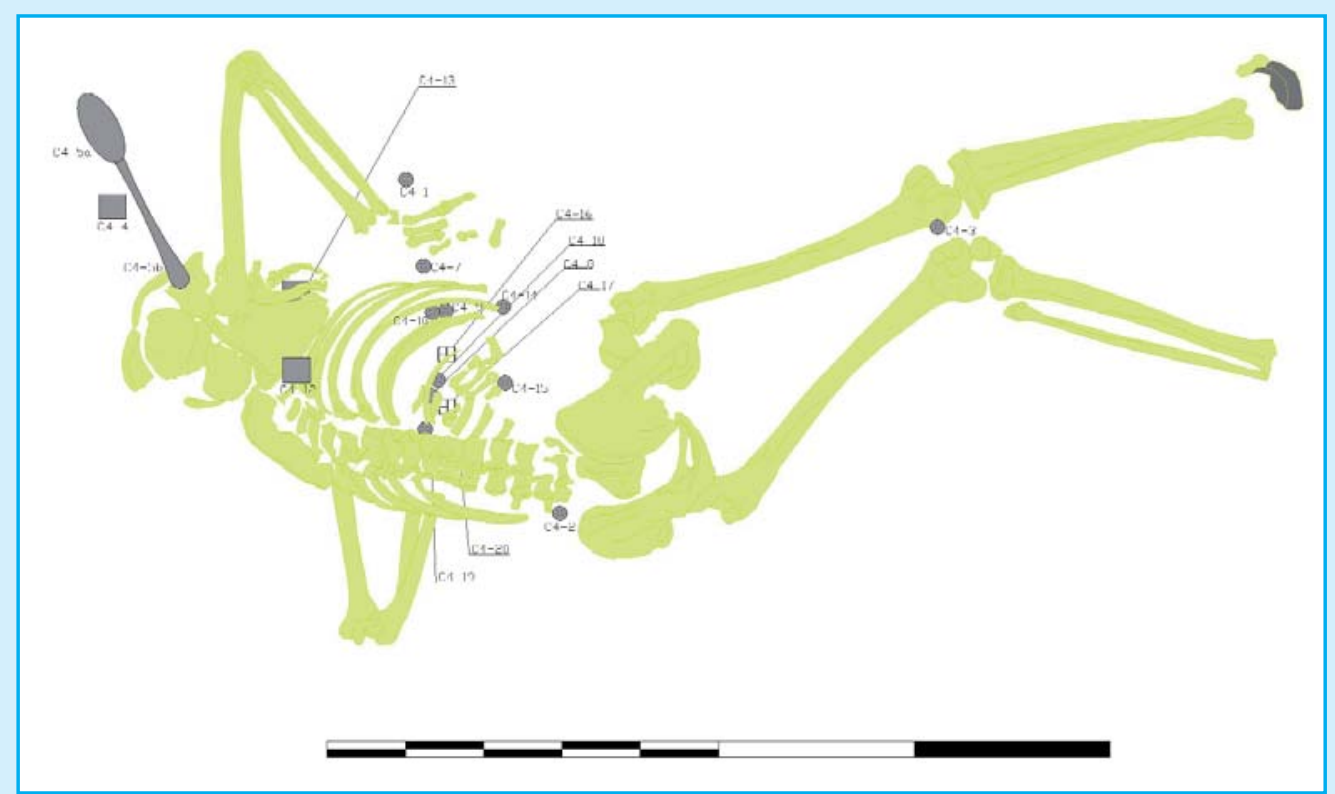


adulto-joven (15-35 años), maduro (35-50 años) y de edad avanzada (más de 50 años) ${ }^{25}$; adicionalmente, se calculó el rango de la edad más probable dentro de un intervalo de cinco años. El estudio osteométrico consistió en el registro de 15 medidas lineales de la región craneal, y 13 medidas directas y 3 índices de robustez de la región postcraneal y se calculó la estatura ${ }^{25-27}$. Asimismo se registraron los caracteres epigenéticos ${ }^{25,28}$, observando aquellos caracteres morfológicos del esqueleto con mayor determinación genética. El análisis de las entesis se concretó en once zonas de la extremidad superior con mayor asociación con actividad ${ }^{29}$. Para el estudio del sistema dental se tuvo en cuenta el estado dental y alveolar, la presencia y tipología de caries, la evidencia de enfermedad periodontal y placa dental, el grado de desgaste y la presencia y la tipología de hipoplasia del esmalte $^{30}$. El estudio de patologías se basó en la observación de alteraciones morfológicas indicativas de patología ante mortem ${ }^{31,32}$.

Les lesiones esqueléticas traumáticas peri mortem se analizaron y categorizaron de acuerdo con su origen y mecanismo ${ }^{1,33}$ y la diferenciación entre lesiones ante mortem y peri mortem se consideró a partir de la remodelación ósea ${ }^{34}$. El diagnóstico de lesiones peri mortem y su diferenciación de procesos tafonómicos se realizó a partir de las características observadas in situ, del análisis del patrón de fracturas observado posteriormente en el laboratorio, de las características de los márgenes de las lesiones, de la presencia de pátina y del estudio de los fragmentos óseos perilesionales ${ }^{35-38}$. Se analizaron las lesiones por arma de fuego, tanto en el campo como en el laboratorio ${ }^{36,39-41}$, teniendo en cuenta de manera específica las lesiones torácicas ${ }^{42,43}$. En todos los casos, el diagnóstico de la causa más probable de muerte se basó en el análisis de las lesiones más letales presentes en cada uno de los esqueletos $^{44,45}$.

El análisis genético se realizó a partir de piezas dentales que se procesaron en tres laboratorios: Instituto de Biología Evolutiva (CSIC-UPF) y la UB, el Departamento de Biología Celular, Fisiología e Inmunología (UAB-BC), y el laboratorio de ADN antiguo de la Unidad de Antropología Biológica del Departamento de Biología Animal, Biología Vegetal y Ecología (UAB-AB), estos dos últimos de la UAB. Las muestras de los familiares se procesaron en el laboratorio de Genética de Poblaciones Humanas, también de la Unidad de Antropología Biológica de la UAB (UAB-AB).

Se tomaron las precauciones y criterios de autentificación recomendados en los estudios de ADN antiguo ${ }^{46}$. La extracción se realizó por procedimientos orgánicos ${ }^{47-48}$ y se amplificaron fragmentos de ADN mitocondrial (ADNmt) y nuclear. Para la caracterización del ADNmt, se trabajó con la región hipervariable 1 (HVR1) y dos pares de primers: L16022-H16218 y L16209-H16378, y un fragmento de la hipervariable 2 (HVR2) L29-H264. Los productos de PCR se clonaron con el kit TOPO TA Cloning kit (Invitrogen, Karlsruhe, Germany), y se secuenciaron aproximadamente 20 secuencias. En relación al cromosoma Y, se utilizó el kit Y-filer (Applied Biosystems) procesando de forma paralela un control positivo, un control negativo (una muestra femenina) y un blanco. En relación a los STR autosómicos, se utilizó el kit Identifiler ${ }^{\circledR}$ PCR (Applied Biosystems).

La superposición de imágenes fotográficas de los cuatro desaparecidos se realizó con cada uno de los cráneos hallados en la fosa. Los cráneos se prepararon para obtener una fotografía en la posición más parecida a la fotografía indubitada de mejor calidad. En cuanto a las fotografías, se escogió la más próxima a la posición Frankfurt (frontal) y de mayor calidad para ser digitalizada. El programa informático utilizado para las superposiciones fue el programa Adobe Photoshop y se tuvieron en cuenta 18 puntos anatómicos: supraorbitario (2), orbital (2), maxilofrontal (2), ectoconquio (2), nasion (1), acantion (1), zígion (2), nasolateral (2), dacrion (2) y el centro pupilar (2) ${ }^{49,50}$ para la comparación ${ }^{51,52}$.

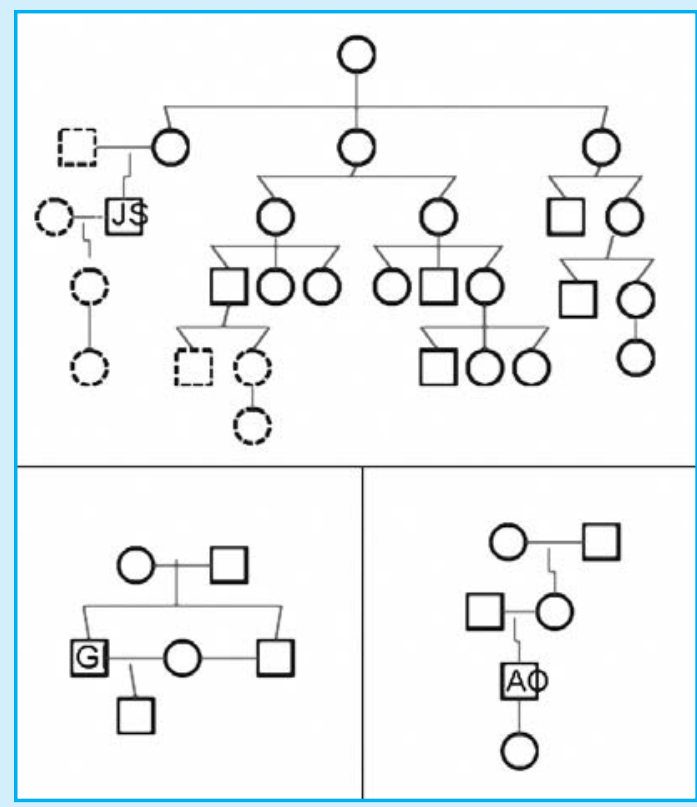

Figura 4. Árboles genealógicos de JS, GI y AO para el análisis molecular. 


\begin{tabular}{rcccc} 
Tabla 1. & Desaparecido & Edad & Talla & Ocupación \\
\cline { 2 - 5 } $\begin{array}{r}\text { Información antemortem } \\
\text { de las cuatro personas } \\
\text { de Gavà. }\end{array}$ & JS & 38 & $171 \mathrm{~cm}$ & Labrador \\
& GI & 40 & $171 \mathrm{~cm}$ & Labrador \\
\hline & AO & 38 & $162 \mathrm{~cm}$ & Labrador \\
\hline JR & 38 & $162 \mathrm{~cm}$ & Labrador \\
\hline
\end{tabular}

\section{Resultados}

Respecto a los datos ante mortem, las limitaciones derivadas del tiempo transcurrido y de la edad de los informantes en el momento de la desaparición, imposibilitaron la obtención de datos significativos relativos a señas y caracteres individualizadores de las cuatro personas desaparecidas. En relación a la información fotográfica, únicamente se pudo disponer de fotografías frontales del AO y JS, mientras que de JR y Gl se obtuvieron fotografía de perfil. Para los análisis genéticos se dispuso de muestras biológicas de dos sobrinas por línea materna de JS, del hijo de GI y la hija de AO (Figura 4). Los expedientes y filiaciones militares facilitadas por el Archivo General Militar de Guadalajara aportaron datos sobre la edad, profesión y talla (Tabla 1 ).

La excavación de la fosa de Gurb proporcionó los restos esqueléticos de 13 individuos adultos y de sexo masculino. Los esqueletos se encontraron parcialmente sobrepuestos entre ellos, nueve de ellos en posición de decúbito prono, uno en posición lateral, y tres en decúbito supino. La disposición de los esqueletos indica que fueron arrastrados por debajo de los brazos o por los pies, accediendo a la fosa por la vertiente sur, siguiendo el eje longitudinal de ésta (Figura 5).

El estado de conservación de los restos era, en general, muy bueno, a pesar de que algunos cráneos resultaron aplastados debido, muy probablemente, al peso del sedimento que los recubría. Únicamente los procesos postdeposicionales naturales afectaron los restos esqueléticos, especialmente los situados en la mitad norte de la fosa y cercanos al margen oriental. Por otro lado, la mayoría de fracturas óseas observadas en la fosa correspondían a lesiones peri mortem relacionadas directamente con la causa de la muerte (Figura 6).

Finalizada la intervención en la fosa de Gurb, se inició el estudio de los restos en el laboratorio. Los principales resultados del análisis arqueológico, antropológico, forense, genético y de superposición craneofacial se resumen en la Tabla 2. En cuanto al análisis genético, se efectuó la caracterización genética de todos los esqueletos. Se obtuvo el perfil mitocondrial de todos los individuos (Tabla 3), mientras que sólo fue parcial a nivel de los marcadores nucleares (STRs autosómicos y del cromosoma Y; (Tablas 4 y 5)). La información morfológica individual de cada esqueleto se resume a continuación.

Figura 5.

Fotografía y esquema de los esqueletos encontrados en la fosa de Gurb.
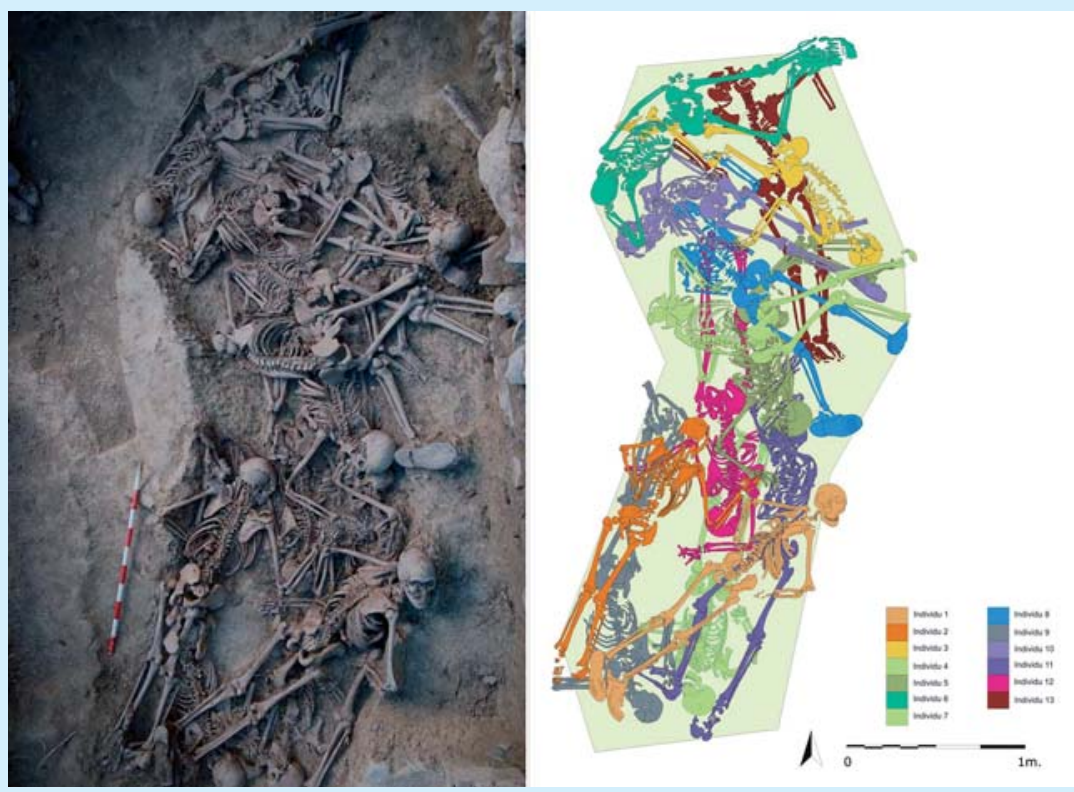


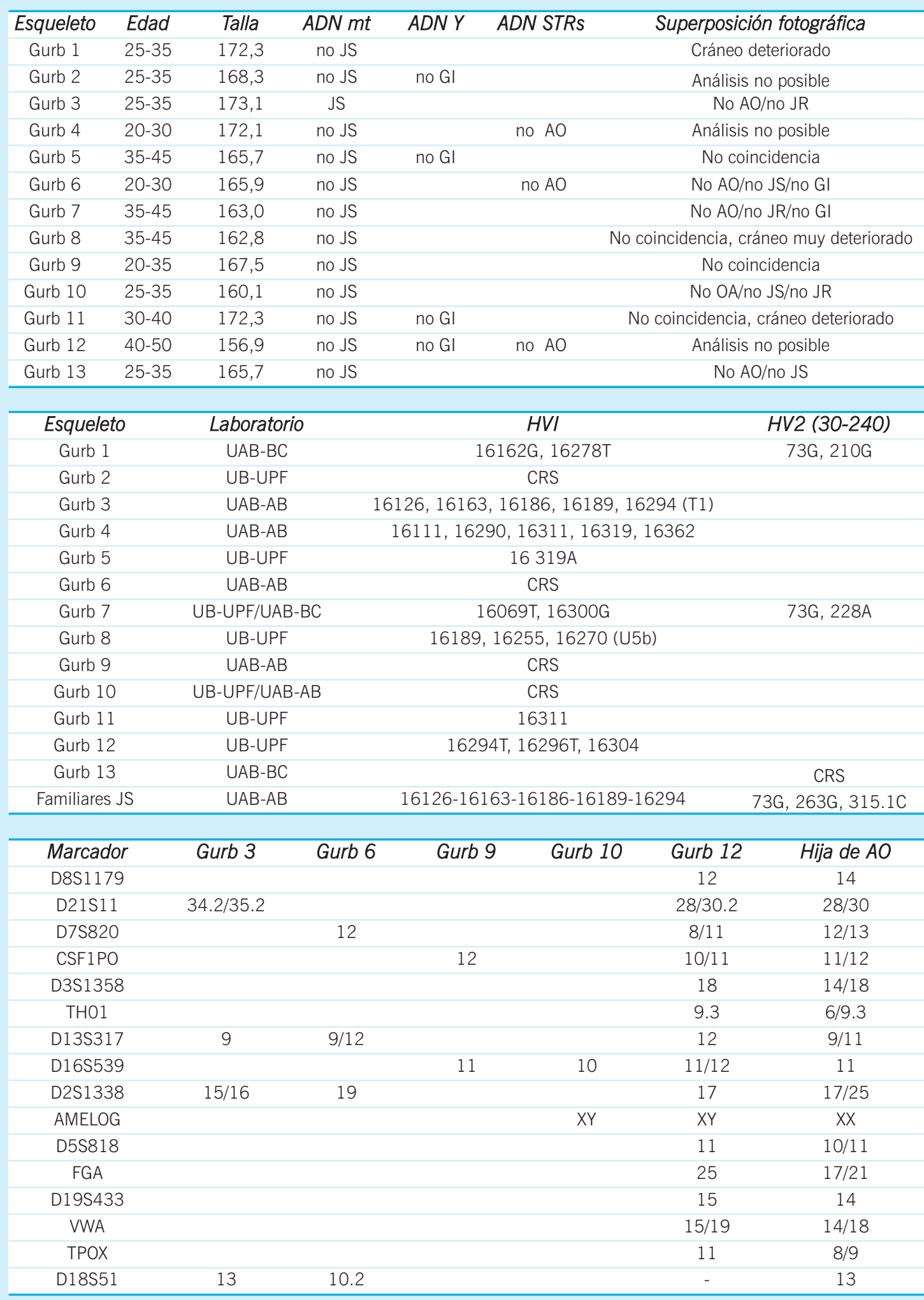

Tabla 2.

Resultados de los análisis morfológicos y moleculares de los restos hallados en la fosa de Gurb.

Tabla 3.

Resultados de los análisis de ADNmt de los restos hallados en la fosa de Gurb.

$U A B-B C$ : Laboratorio de la Unidad de Biología Celular de la $U A B$; UAB-AB: Laboratorio de la Unidad de Antropología Biológica de la UAB; UB-UPF: Laboratorio de la Unidad de Antropología Biológica de la UB e Instituto de Biología Evolutiva (CSIC-UPF).

Tabla 4.

Resultados de los análisis positivos de STRs y de amelogenina realizados a partir de los restos humanos hallados en la fosa de Gurb (UAB-AB, UB-UPF). 


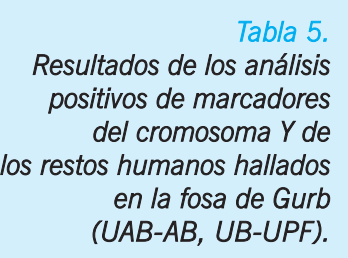

\begin{tabular}{|cccccc}
\hline Marcador & $\begin{array}{c}\text { Gurb } \\
2\end{array}$ & $\begin{array}{c}\text { Gurb } \\
5\end{array}$ & $\begin{array}{c}\text { Gurb } \\
11\end{array}$ & $\begin{array}{c}\text { Gurb } \\
12\end{array}$ & $\begin{array}{c}\text { Hijo } \\
\text { de GI }\end{array}$ \\
\hline B_DYS456 & & 15 & & & 15 \\
\hline B_DYS389I & 13 & 13 & & 13 & 13 \\
\hline B_DYS390 & 24 & 24 & & 24 & 25 \\
\hline B_DYS389II & 29 & 29 & & 29 & 30 \\
\hline G_DYS458 & & 16 & & & 16 \\
\hline G_DYS19 & & 19 & & & 16 \\
\hline G_DYS385I & 11 & 12 & 13 & 11 & 10 \\
\hline G_DYS385II & 14 & & & & 14 \\
\hline Y_DYS393 & 13 & 13 & & & 13 \\
\hline Y_DYS391 & 10 & 11 & & 10 & 11 \\
\hline Y_DYS439 & & 12 & & & 13 \\
\hline Y_DYS635 & & 23 & & & 23 \\
\hline Y_DYS392 & & 13 & & & 13 \\
\hline R_Y_GATA_H4 & & 12 & & & 12 \\
\hline R_DYS437 & 14 & 15 & 16 & & 16 \\
\hline R_DYS438 & & 12 & & & 12 \\
\hline R_DYS448 & 18 & 19 & & 18 & 19 \\
\hline
\end{tabular}

Figura 6.

Lesiones sufridas por el individuo 8 y reconstrucción de las trayectorias de los disparos.
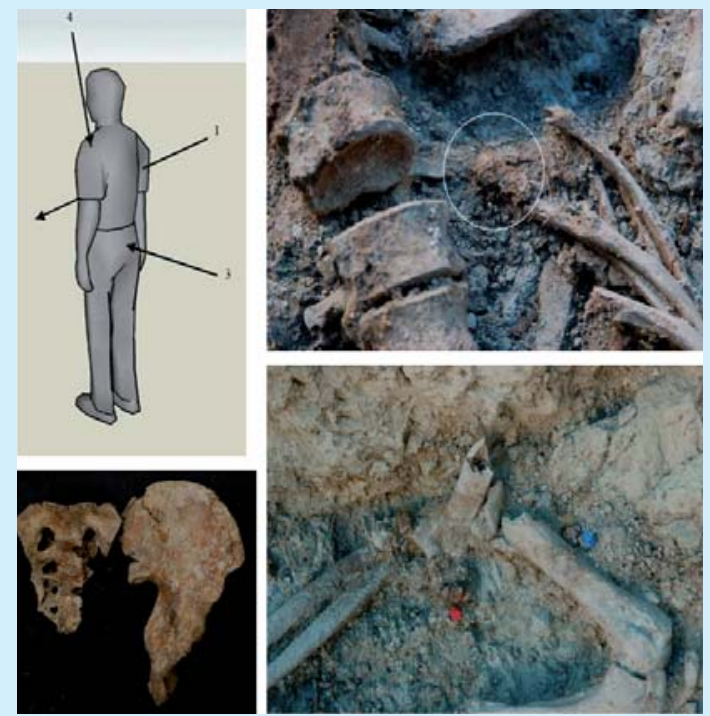

\section{Esqueleto 1}

Individuo masculino adulto-joven, de 25-35 años, y estatura aproximada de $172 \mathrm{~cm}$, situado en la mitad sur de la fosa, en posición de decúbito prono, inhumado probablemente en último lugar (Figura 6). Asociado a este individuo se encontró un lápiz.

Presenta una robustez de los huesos largos inferior a la media de la muestra y un desarrollo de la muscu-

latura de la extremidad superior entre débil y moderado. También destaca una espina bífida oculta a nivel de la región sacra, incisivos en pala y tubérculo de Carabelli. En relación a la patología ante mortem, presenta una espondilosis de carácter leve y una leve patología oral, caracterizada por algunas pérdidas dentales y caries.

El individuo 1 sufrió un mínimo de una lesión por impacto de proyectil de arma de fuego (Figura 7.1), y se establece como diagnóstico de la causa inmediata de muerte una lesión neurológica/destrucción de centros vitales y como causa intermedia: traumatismo craneoencefálico abierto.

\section{Esqueleto 2}

Individuo masculino adulto-joven, de 25-35 años, y estatura aproximada de $168 \mathrm{~cm}$, situado en la mitad sur del margen occidental de la fosa, en posición de decúbito prono, inhumado probablemente en penúltimo lugar (Figura 6).

Muestra una robustez de los huesos largos inferior a la media del grupo, pero un fuerte desarrollo de la musculatura de los hombros y débil de la correspondiente a la mano. Igualmente, destaca una espina bífida oculta a nivel de la región lumbar, una doceava costilla muy reducida, tubérculo dental en el incisivo superior lateral y tubérculo de Carabelli. En relación a la patología ante mortem destaca una espondilosis moderada y una osteocondritis que afectó el acetábulo izquierdo; en cuanto a la patología oral, presenta caries, pérdidas dentales y una fístula.

El individuo sufrió un mínimo de cuatro lesiones por impacto de proyectil de arma de fuego (Figura 7.2), y se establece como diagnóstico de la causa inmediata de muerte: lesión neurológica/destrucción de centros vitales, y como causa intermedia: traumatismo craneoencefálico y torácico abiertos.

\section{Esqueleto 3}

Se trata de un individuo masculino adulto-joven, de 25-35 años, y estatura aproximada de $173 \mathrm{~cm}$, situado en la mitad norte del margen oriental de la fosa, en posición de decúbito lateral izquierdo y pronación de la parte inferior del cuerpo. Fue inhumado probablemente en décimo lugar (Figura 6).

Destaca la presencia de incisivos en forma de pala, y de tubérculos accesorios a nivel de los molares tanto superiores como inferiores. En relación a la patología ante mortem, muestra una entesopatía a nivel costoclavicular derecho y una osteocondritis tibioastragalina bilateral; en cuanto a patología oral, sufrió diversas pérdidas dentales y una leve periodontopatía. 


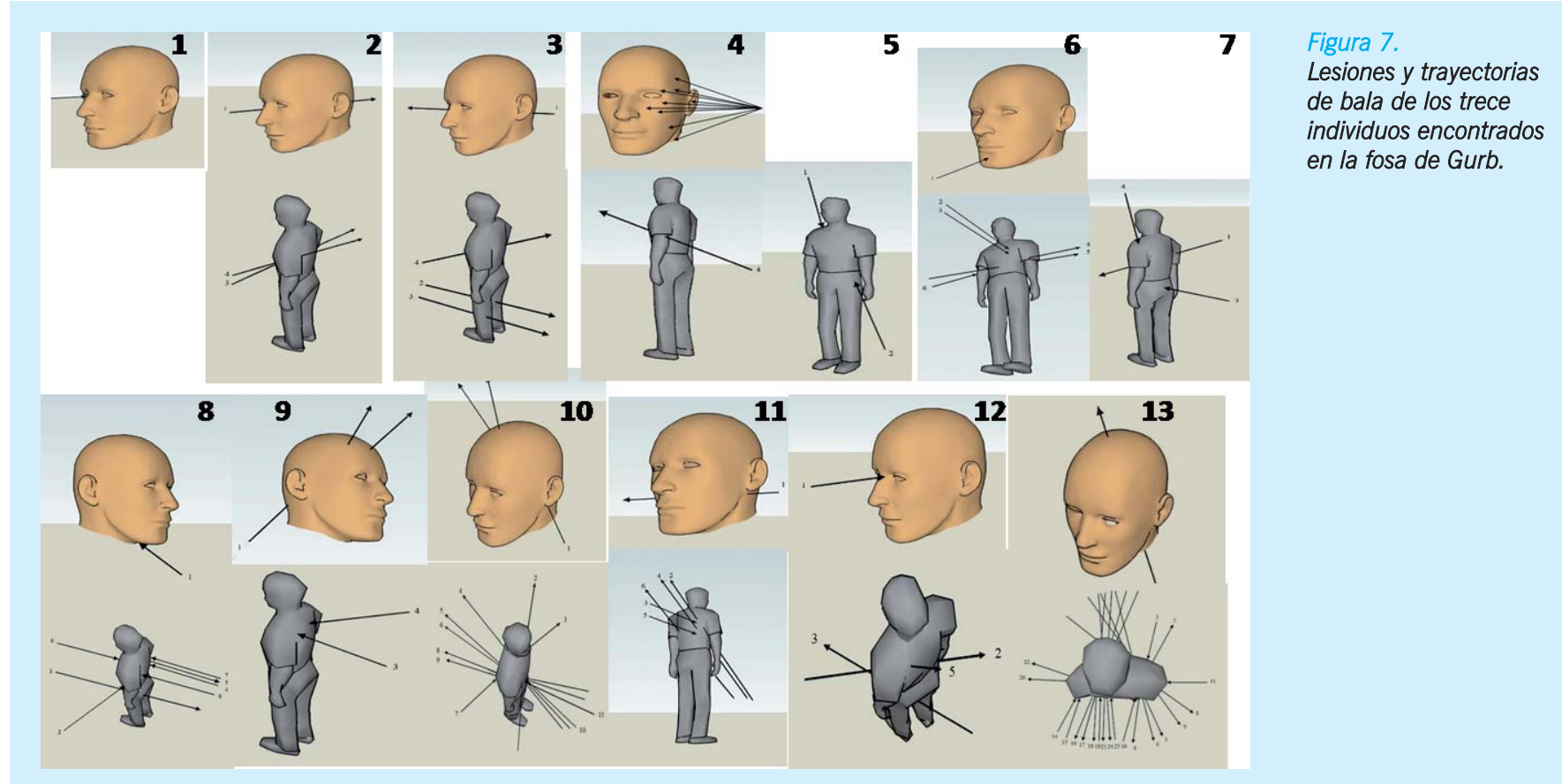

El individuo sufrió un mínimo de cuatro lesiones por impacto de proyectil de arma de fuego (Figura 7.3), y se establece como diagnóstico de causa inmediata de muerte: lesión neurológica/destrucción de centros vitales, y como causa intermedia: traumatismo craneoencefálico y torácico abiertos.

\section{Esqueleto 4}

Individuo masculino adulto-joven, de 20-30 años, y estatura aproximada de $172 \mathrm{~cm}$, situado en el cuadrante central de la fosa y colocado perpendicular al eje longitudinal de ésta, en posición de decúbito prono, inhumado probablemente en octavo lugar (Figura 6). Asociado a este individuo se encontró una cuchara.

Presenta un desarrollo moderado de la musculatura de la extremidad superior, predominantemente de la derecha, lo que sugiere que el individuo era diestro. También destaca la presencia de tubérculo dental y surco en los incisivos laterales superiores, y cresta accesoria distal en los caninos superiores. En relación con la patología ante mortem, destaca la presencia de una posible malformación a nivel costal izquierdo.

El individuo sufrió un mínimo de dos lesiones por impacto de proyectil de arma de fuego (Figura 7.4). Se podido determinar la implicación de cómo mínimo un arma de proyectiles múltiples, y se establece como diagnóstico de causa inmediata de muerte: lesión neurológica/destrucción de centros vitales, y como causa intermedia: traumatismos craneoencefálico y cervical abiertos.

\section{Esqueleto 5}

Individuo masculino adulto-maduro, de 35-45 años, y estatura aproximada de $166 \mathrm{~cm}$, situado en la parte central de la fosa siguiendo el eje longitudinal de ésta, en posición de decúbito prono, inhumado probablemente en quinto lugar (Figura 6).

Destaca la presencia de un foramen esternal y malposición de las piezas dentales anteriores mandibulares. En relación a la patología ante mortem, destaca la patología oral, caracterizada por diversas pérdidas dentales y periodontopatía, artrosis a nivel esternoclavicular, espondilosis moderada, espondilólisis de la cuarta lumbar, epifisitis de la quinta lumbar y una enteropatía exostósica en la tuberosidad bilateral del calcáneo.

El individuo sufrió un mínimo de dos lesiones por impacto de proyectil de arma de fuego (Figura 7.5). Se ha podido determinar la implicación de cómo mínimo un arma larga, y se establece como diagnóstico de la causa inmediata de la muerte: choque hipovolémico, y como causa intermedia: traumatismos torácico y pélvico abiertos. 


\section{Esqueleto 6}

Individuo masculino adulto-joven, de 20-30 años, y estatura aproximada de $166 \mathrm{~cm}$, situado en el margen norte de la fosa, en posición de decúbito supino, inhumado probablemente en onceavo lugar (Figura 6).

Como características individualizadoras muestra un hueso epactal, cresta distal accesoria en los caninos superiores, tubérculo de Carabelli e incisivos mandibulares en forma de pala.

El individuo sufrió un mínimo de cuatro lesiones por impacto de proyectil de arma de fuego (Figura 7.6). Se ha podido determinar la implicación de cómo mínimo un arma larga, y se establece como diagnóstico de la causa inmediata de la muerte: choque hipovolémico, y como causa intermedia: traumatismos torácico y cérvicofacial abiertos.

\section{Esqueleto 7}

Individuo masculino adulto-maduro, de 35-45 años, y estatura aproximada de $163 \mathrm{~cm}$, situado en contacto directo con la base de la fosa, siguiendo el eje longitudinal, y el cráneo muy cerca de la pared sur. Fue inhumado probablemente en séptimo lugar en posición de decúbito supino (Figura 6).
Presenta un desarrollo moderado de la musculatura de la extremidad superior, con predomino del desarrollo de la musculatura de la mano izquierda, lo que sugiere que el individuo era zurdo. Destaca la presencia de espina bífida oculta a nivel del sacro. En relación con la patología ante mortem, presenta una fractura consolidada en clavícula derecha, un pectus carinatum (Figura 8), una ligera espondilosis, una fractura astragalina bilateral y una importante patología oral, caracterizada per pérdidas dentales, fístulas, caries y periodontopatía.

El individuo sufrió un mínimo de cuatro lesiones por impacto de proyectil de arma de fuego (Figura 7.7) y se establece como diagnóstico de causa inmediata de la muerte: choque hipovolémico, y como causa intermedia: traumatismos torácico, pélvico y de extremidad superior derecha abiertos.

\section{Esqueleto 8}

Individuo masculino adulto-maduro, de 35-45 años, y estatura aproximada de $162 \mathrm{~cm}$, situado en la parte central norte de la fosa, en posición de decúbito prono, inhumado probablemente en cuarto lugar (Figura 6). Se encontró una funda de navaja asociada a él.

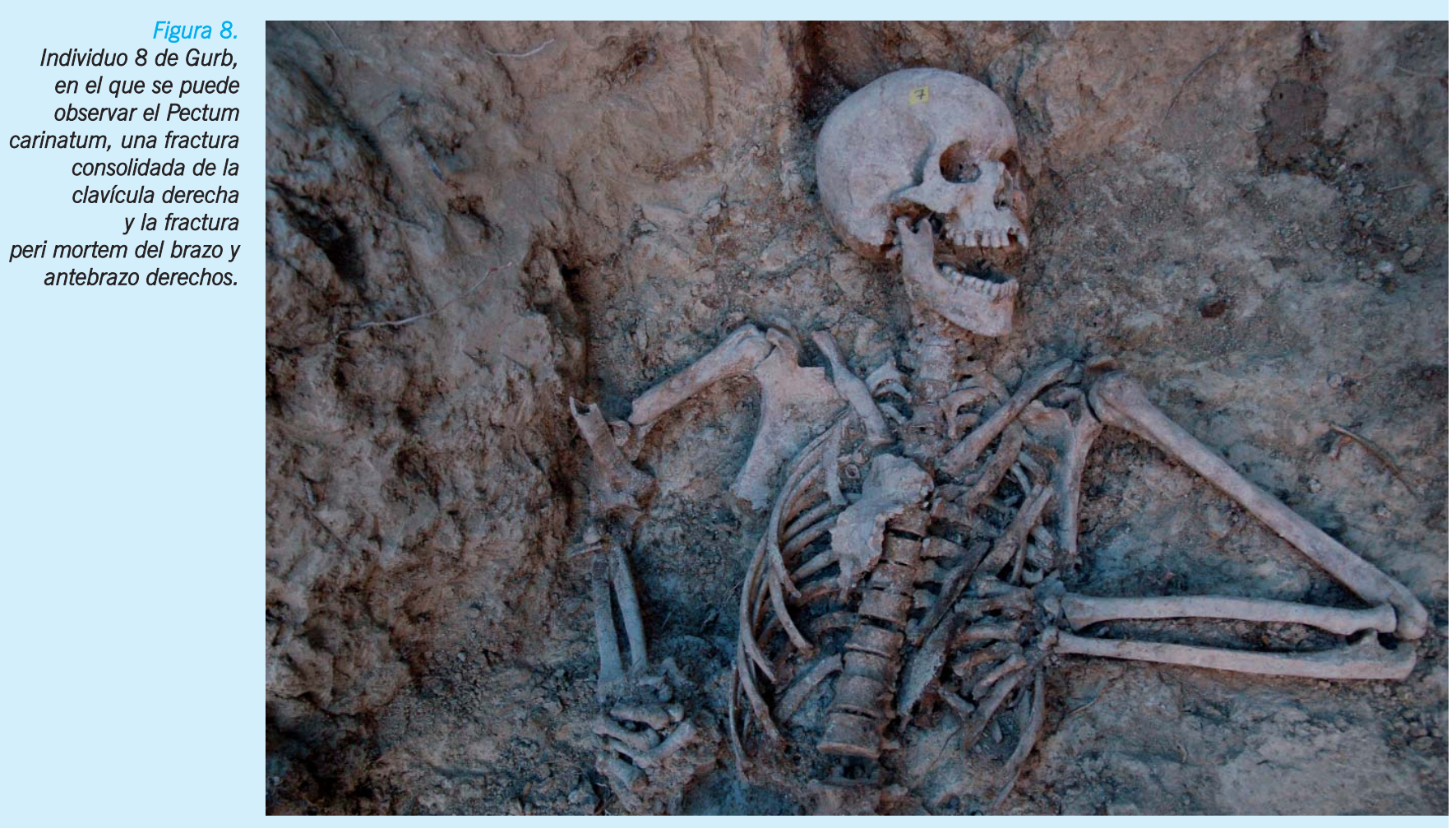


Destaca la presencia de tubérculo de Carabelli. En relación con la patología ante mortem, presenta una importante patología oral, con pérdidas dentales, fístulas, caries y periodontopatía; también presenta signos artrósicos en la articulación gleno-humeral derecha, una espondilosis leve, engrosamiento diafisal en los huesos del quinto dedo de la mano izquierda y una fisura reciente a nivel de cuello femoral izquierdo indicativa de que el individuo sufrió un episodio traumático en días previos a su muerte.

El individuo sufrió un mínimo de siete lesiones por impacto de proyectil de arma de fuego (Figura 7.8) y se diagnostica como causa inmediata de la muerte: lesión neurológica/destrucción de centros vitales, y como causa intermedia: traumatismos torácico, de extremidad superior e inferior izquierda, y craneoencefálico abiertos.

\section{Esqueleto 9}

Individuo masculino adulto-joven, de 25-35 años, y estatura aproximada de $168 \mathrm{~cm}$, cuyo cráneo se hallaba muy cerca del margen sur de la fosa y los pies en contacto con el margen occidental, en posición de decúbito prono, inhumado probablemente en tercer lugar (Figura 6). Asociado a él se encontró una mina de lápiz y una cuchara.

Presenta una robustez de los huesos largos superior a la media del grupo y un desarrollo importante de la musculatura de la espalda, moderado del antebrazo y débil de las manos. Asimismo destaca la presencia de tubérculo de Carabelli e incisivos, tanto superiores como inferiores, en forma de pala. En relación a la patología ante mortem, presenta una ligera espondilosis y diversas entesopatías en la musculatura del hombro de forma bilateral, que sugiere una actividad repetitiva con implicación de la cintura escapular.

El individuo sufrió un mínimo de cuatro lesiones por impacto de proyectil de arma de fuego (Figura 7.9) y se diagnostica como causa inmediata de la muerte: lesión neurológica/destrucción de centros vitales, y como causa intermedia: traumatismos torácico, de extremidad superior izquierda, y craneoencefálico abiertos.

\section{Esqueleto 10}

Individuo masculino adulto-maduro, de 30-40 años, y estatura aproximada de $160 \mathrm{~cm}$, situado en la zona norte de la fosa, perpendicular al eje mayor, en posición de decúbito prono, inhumado probablemente en noveno lugar (Figura 6). Junto a él se encontró una cuchara.
Se ha observado un desarrollo importante de la musculatura del hombro, moderado del antebrazo y débil de las manos, lo que sugiere una actividad repetitiva con implicación de la cintura escapular. Destaca la presencia de tubérculo de Carabelli, un fuerte desarrollo del tubérculo dental de los incisivos y caninos superiores, y una escotadura del margen lateral de ambas rótulas. En relación a la patología ante mortem, presenta espondilólisis de la quinta vértebra lumbar, entesopatía del dorsal ancho y el costoclavicular, y una importante patología oral, caracterizada por pérdidas dentales, fístulas, caries y periodontopatía.

El individuo sufrió un mínimo de nueve lesiones por impacto de proyectil de arma de fuego (Figura 7.10) y se establece como causa inmediata de la muerte: lesión neurológica/destrucción de centros vitales, y como causa intermedia: traumatismos craneoencefálico, torácico, y pélvico abiertos

\section{Esqueleto 11}

Individuo masculino adulto, de 30-40 años, y estatura aproximada de $172 \mathrm{~cm}$, situado en la mitad sur de la fosa, en posición de decúbito supino, inhumado probablemente en primer lugar (Figura 6). Junto a él se encontró una aguja imperdible.

Destaca la presencia de tubérculo de Carabelli, y malposición de las piezas dentales anteriores mandibulares. En relación a la patología ante mortem, presenta una importante patología oral, con pérdidas dentales, caries, periodontopatía y un proceso infeccioso agudo con una fístula de drenaje que seguramente afectó al individuo en los días previos a su muerte. También presenta una ligera espondilosis.

El individuo sufrió un mínimo de seis lesiones por impacto de proyectil de arma de fuego (Figura 7.11) y se establece como diagnóstico de la causa inmediata de la muerte: lesión neurológica/destrucción de centros vitales y como causa intermedia: traumatismos torácico y craneoencefálico abiertos

\section{Esqueleto 12}

Individuo masculino adulto-maduro, de 40-50 años, y estatura aproximada de $157 \mathrm{~cm}$, situado en la parte central de la fosa, en posición de decúbito prono, inhumado probablemente en segundo lugar (Figura 6). Junto a él se encontró un cristal quizás perteneciente a un marco de fotografías.

Presenta un desarrollo importante de la musculatura de la extremidad superior. Cabe destacar la presencia de tubérculo de Carabelli y surco en el 
cingulum del incisivo lateral superior derecho. En relación a la patología ante mortem, presenta una fractura de Colles del radio derecho, espondilosis importante y entesopatías de los ligamentos costoclavicular derecho y rotuliano, y una importante patología oral, caracterizada por pérdidas dentales, caries y fístulas. Así mismo, presenta una fractura o hundimiento del cuerpo de la doceava vértebra dorsal, que sugiere que el individuo sufrió un episodio traumático antes de su muerte.

El individuo sufrió un mínimo de cinco lesiones por impacto de proyectil de arma de fuego (Figura 7.12). Se ha podido determinar la implicación de como mínimo un arma larga y se establece como diagnóstico de la causa inmediata de la muerte: lesión neurológica/destrucción de centros vitales y como causa intermedia: traumatismos craneoencefálico, torácico y pélvico abiertos

\section{Esqueleto 13}

Individuo masculino adulto-joven, de 25-35 años, y estatura aproximada de $166 \mathrm{~cm}$, situado en la mitad norte de la fosa siguiendo su eje longitudinal, en posición de decúbito prono, inhumado probablemente en sexto lugar (Figura 6).

En relación a la patología ante mortem, presenta una pérdida dental, una caries y periodontopatía, así como espondilólisis de la quinta vértebra lumbar.

El individuo sufrió un mínimo de catorce lesiones por impacto de proyectil de arma de fuego (Figura 7.13) y se diagnostica como causa inmediata de la muerte: lesión neurológica/destrucción de centros vitales, y como causa intermedia: traumatismos torácico y craneoencefálico abiertos.

\section{Consideraciones generales}

En total se recuperaron los restos de 13 personas atribuidos a hombres adultos, la mayoría adultos jóvenes. El análisis antropológico y forense evidenció numerosas fracturas peri mortem, la mayoría relacionadas con la presencia de balas. Se recuperaron, asimismo, un número importante de objetos, principalmente botones y munición, percutida y sin percutir; también, otros objetos metálicos como hebillas y cucharas, y restos de textiles muy deteriorados.

En cuanto a la identificación, los datos morfológicos no fueron muy definitorios, ya que las cuatro personas que se buscaban eran del mismo sexo, tenían edades parecidas (38, 38, 38 y 39 años), la misma ocupación (campesinos) y tallas también parecidas $(162,162,171,171 \mathrm{~cm})$. En cuanto a enfermedades ante mortem, sólo se conocía que JS sufrió fiebres de Malta y un accidente en el pie con una horca.

Sin embargo, el conjunto de datos morfológicos y genéticos permite afirmar la identidad del esqueleto núm. 3 como el de JS, ya que el perfil mutacional de su ADNmt coincide con el de los familiares, es muy poco frecuente, y no se ha encontrado la misma combinación de mutaciones en ningún otro individuo de la fosa. Se trata, pues, de una identificación positiva fehaciente.

Respecto a los otros tres vecinos de Gavà, se puede aportar una identificación positiva probable. Las informaciones militares en relación con Gl indican una talla de $171 \mathrm{~cm}$. Solamente cuatro esqueletos de la fosa se corresponden con una estatura superior a $170 \mathrm{~cm}$. Descartados los esqueletos $n^{\circ} 3$ (identificado como JS) y el $n^{\circ} 11$ (no coincidencia con los marcadores del cromosoma $Y$ de su hijo JI), sólo restan los esqueletos 1 y 4 . Atendiendo al rango de edad diagnosticado y la compatibilidad de características morfológicas del cráneo es probable que se trate del esqueleto núm. 1.

Respecto a AO, la ficha militar proporciona una estatura de $161,5 \mathrm{~cm}$. Los datos morfológicos (por ejemplo, la aproximación métrica y de edad) lo hacen compatible principalmente con los esqueletos 7 y 8 . Entre ambos, la fisonomía obtenida a partir de la fotografía de AO (frente ancha y vertical, con protuberancias frontales marcadas, nariz estrecha y alta, órbitas redondeadas, y mentón alto y redondeado) es compatible principalmente con el cráneo del esqueleto $n^{\circ} 7$, si bien la superposición de imágenes no ha permitido una resolución positiva. Por otra parte, los datos moleculares indican que el esqueleto n 8 no puede pertenecer a AO (STR autosómicos).

Respecto a JR, la ficha militar proporciona una estatura muy parecida a la anterior, $162 \mathrm{~cm}$, que coincide con la de los esqueletos anteriores, 7 y 8 . Por otro lado los datos morfológicos son compatibles con el esqueleto $n^{\circ} 8$, por lo que consideramos que es probable que el esqueleto $n^{0} 8$ corresponda a JR.

En relación a las circunstancias y las causas de muerte, en todos los casos la causa fundamental fueron las lesiones por proyectil de arma de fuego que causaron lesiones a diversos niveles: craneoencefálico, facial, torácico y en las extremidades. El número, variedad y localización de las lesiones son compatibles con un contexto de batalla.

Así pues, en conclusión se ha podido identificar de manera fehaciente el esqueleto $\mathrm{n}^{\circ} 3$ como el de JS, mientras que la correspondencia entre el esqueleto $\mathrm{n}^{\circ} 1$ y Gl, el esqueleto $\mathrm{n}^{\circ} 7$ y $\mathrm{AO}$, y el esqueleto $n^{\circ} 8$ y JR, aportan una identificación positiva probable. 
El análisis de las causas de muerte permite afirmar que todos los individuos murieron como consecuencia de lesiones por arma de fuego, probablemente en un contexto de batalla.

\section{Agradecimientos}

Este trabajo ha sido posible gracias a la financiación de la Generalitat de Catalunya y el convenio

\section{Bibliografía}

1. Cattaneo C. Forensic anthropology: developments of a classical discipline in the new millennium. Forensic Science International 2007;165:185-93.

2. Ibars M, Malgosa A. ¿Dónde está el Príncipe de Viana? Los análisis de ADN mitocondrial. Revista de Arqueología 2009;331: 40-51.

3. Cockburn A, Cockburn E, Reyman TA (eds). Mummies, diseases and ancient cultures. Cambridge: Cambridge University Press, 1998.

4. Harris JE, Hussien F. The Identification of the Eighteenth Dynasty Royal Mummies; a Biological Perspective. International Journal of Osteoarchaeology 1991;1:235-9.

5. Solé Q. Els morts clandestins. Les fosses comunes de la Guerra Civil a Catalunya (1936-1939). Catarroja, Valencia: Ed. Afers 2008.

6. Harris E. Principios de estratigrafía arqueológica. Barcelona: Ed. Crítica. 1991.

7. Brothwell D. Digging up Bones. London: British Museum (Natural History) 1981.

8. Duday H, Courtaud P, Crubezy E, Sellier P, Tillier AM. L'anthropologie "de terrain": reconnaissance et interprétation des gestes funéraires. Bull. et Mém. Soc. d'Anthrop. Paris 1990;(3-4):191-200.

9. Krogman WM, Iscan MY. The human skeleton in forensic medicine. Springfield, Illinois: Ch. C. Thomas Publ. 1986.

10. Crétot M. L'arcade Dentaire Humaine (Morphologie). París: Julien Prélat. 1978. realizado entre los Departaments de Interior, Relacions Institucionals i Participació i Justícia de la Generalitat de Catalunya, la Universitat de Barcelona i la Universitat Autònoma de Barcelona.

También debemos agradecer la colaboración de muchas personas implicadas en la búsqueda y recuperación de información, y la de los familiares de los desaparecidos.

11. Ferembach D, Schwidetzky I, Stloukal M. Recommendations for age and sex diagnoses of skeletons. Bull. et Mém. Soc. d'Anthrop. Paris 1979;6(1):7-45.

12. Acsádi GY, Nemeskéri J. History of Human Life Span and Mortality. Budapest, 1970.

13. Aleman I, Botella M, Ruiz L. Determinación del sexo en el esqueleto postcraneal. Estudio de una población mediterránea actual. Archivo Español de Morfología 1997;2:7-17.

14. Safont S, Malgosa A, Subira ME. Sex assessment on the basis of long bone circumference. Am. J. Phys. Anthrop. 2000;113(3):317-28.

15. Olivier G. Pratique Anthropologique. París: Vigot Frères. 1960.

16. Black S, Scheuer L. Age changes in the clavicle: From the early neonatal period to skeletal maturity. International Journal of Osteoarchaeology 1996;6(5):425-34.

17. Ubelaker DH. Human Skeletal Remains: Excavation, Analysis, Interpretation. Taraxacum. Washington DC: Washington, 1989.

18. Todd TW. Age changes in the pubic bone: I. The white male pubis. Am. J. Phys. Anthrop. 1920;3:467-70.

19. Gilbert BM, McKern TW. Method for aging female os-pubis. Am. J. Phys. Anthrop. 1973;38(1):31-8.

20. Brooks ST, Suchey JM. Skeletal age determination based on the os pubis: A comparison of the Acsadi-Nemeskéri and Suchey-Brooks methods. Hum. Evol. 1990;5:227-38. 
21. Lovejoy CO, Meindl RS, Pryzbeck TR, Mensforth RP. Chronological metamorphosis of the auricular surface of the ilium - a new method for the determination of adult skeletal age at death. Am. J. Phys. Anthrop. 1985;68(1):15-28.

22. Buckberry JL, Chamberlain AT. Age estimation from the auricular surface of the ilium: A revised method. Am. J. Phys. Anthrop. 2002;119(3):231-9.

23. Iscan MY, Loth SR, Scheuerman EH. Determination of age from the sternal rib in white females: A test of the phase method. J. Forensic Sciences 1985;31:990-9.

24. Iscan MY, Loth SR, Wright RK. Metamorphosis at the sternal rib end - a new method to estimate age at death in white males. Am. J. Phys. Anthrop. 1984;65(2): 147-56.

25. Buikstra J, Ubelaker D. Standards for Data Collection from Human Skeletal Remains. Arkansas Archaeological Survey Research Series, 44. 1994.

26. de Mendonca MC. Estimation of height from the length of long bones in a Portuguese adult population. Am. J. Phys. Anthrop. 2000;112(1):39-48.

27. Martin R, Saller K. Lehrbuch der Anthropologie. Stuttgart: Fischer G, Ed. 1957.

28. Turner CG, Nichol CR, Scott GR. Scoring Procedures for Key Morphological Traits of the Permanent Dentition: The Arizona State University Dental Anthropology System. En: Kelley MA, Larsen CS (eds). Advances in Dental Anthropology. New York: Wiley-Liss, 1991:13-31.

29. Galtés I, Rodriguez-Baeza A, Malgosa A. Mechanical morphogenesis: A concept applied to the surface of the radius. Anatomical Record Part A-Discoveries in Molecular Cellular and Evolutionary Biology 2006;288A(7):794-805.

30. Chimenos E, Safont S, Alesan A, Alfonso J, Malgosa A. Propuesta de protocolo de valoración de parámetros en Paleodontología. Gaceta Dental 1999;102:44-52.
31. Campillo D. Introducción a la Paleopatología. Barcelona: Edicions Bellaterra SL. 2001.

32. Isidro A, Malgosa A (eds). Paleopatología. La enfermedad no escrita. Barcelona: Masson, SA. 2003.

33. Maples WR. Trauma analysis by the forensic anthropologist. En: Reichs KJ (ed). Forensic Osteology: Advances in the Identification of Human Remains. Springfield: Charles C Thomas 1986;218-28.

34. Sauer NJ. The Timing of injuries and manner of death: distinguishing among antemortem, perimortem and postmortem trauma. En: Reichs KJ (ed). Forensic Osteology. Advances in the Identification of Human Remains. Springfield: Charles C Thomas Publisher, LTD. 1998:321-32.

35. Walker PL. A bioarchaeological perspective on the history of violence. Annual Review of Anthropology 2001;30:573-96.

36. Etxeberria F. Lesiones por arma de fuego. Problemas médico-forenses. Kirurgia 4. San Sebastián, 2003.

37. Kanz F, Grossschmidt K. Head injuries of roman gladiators. Forensic Science International 2006;160:207-16.

38. Tung TA. Trauma and violence in the Wari empire of the Peruvian Andes: Warfare, raids, and ritual fights. Am. J. Phys. Anthrop. 2007;133:941-56.

39. Spitz W. Gunshot wounds. En: Spitz W, Fisher $\mathrm{R}$ (ed). Medicolegal investigation of death: guidelines for the application of pathology to crime investigation. Springfield: Charles C. Thomas 1980:216-75.

40. Berryman HE, Symes SA. Recognizing gunshot and blunt cranial trauma through fracture interpretation. En: Reichs KJ (ed). Forensic Osteology. Advances in the Identification of Human Remains. Springfield: Charles C Thomas Publisher, LTD. 1998:333-51.

41. DiMaio V, DiMaio D. Forensic Pathology, $2^{a}$ ed. Boca Raton, FI: CRC Press 2001.

42. Langley NR. An Anthropological Analysis of Gunshot Wounds to the Chest. Journal of Forensic Science 2007;52:532-7. 
43. Ubelaker DH. The remains of Dr. Carl Austin Weiss: an anthropological analysis. Journal of Forensic Science 1996:41:60-79.

44. Baraybar JP, Gasior M. Forensic anthropology and the most probable cause of death in cases of violations against International Humanitarian Law: an example from Bosnia and Herzegovina. Journal of Forensic Sciences 2006:51:103-8.

45. Pinheiro J. Introduction to Forensic Medicine and Pathology. En: Schmitt A, Cunha E, Pinheiro J. Introduction to forensic medicine and pathology. Totowa NJ: Humana Press 2006:13-37.

46. Poinar HN. The top 10 list: criteria of authenticity for DNA from ancient and forensic samples International Congress Series. Progress in Forensic Genetics 9. 2003;1239:575-9.

47. Lalueza-Fox C, Römpler H, Caramelli D, Stäubert C, Catalano G, Hughes D, Rohland N, Pilli E, Longo L, Condemi S, De La Rasilla M., Fortea J, Rosas A, Stoneking $M$, Schöneberg T, Bertranpetit J, Hofreiter M. A melanocortin 1 receptor suggests variying pigmentation among Neanderthals. Science 2007;318:1453-5.

48. Malgosa A, Montiel R, Díaz N, Solórzano E, Smerling A, Isidro A, García C, Simon M. Ancient Dna: A Modern Look At The Infections Of The Past. Recent research developments in microbiology 2005;9:21336.

49. Rodríguez Cuenca JV. Introducción a la Antropología Forense. Análisis e interpretación de Restos óseos humanos. Santa Fe de Bogotà: Anaconda Editores 1994.

50. Villalaín Blanco JD, Puchalt Fortea FJ. Identificación antropológica policial y forense. Valencia: Ed Tirant lo Blanch 2000.

51. Majumdar T, Sinha P. Photographs of the human face and broken projective symmetry. J. Forensic Sci. 1989;29:381-95.

52. Merabishvili G. Superposición de imagenes. Identificación facial bidimensional. Tesis Doctoral. Universitat de Barcelona. 2006. 